\title{
DESENVOLVIMENTO DE APTÂMEROS COMO FERRAMENTA DE DIAGNÓSTICO PARA CÂNCER DE PULMÃO
}

\author{
Juliana Baranova ${ }^{1}$, Yuli S. Torres ${ }^{1}$, Isis C. Nascimento ${ }^{1}$, Vanessa de Sá ${ }^{1,2 *}$, Henning Ulrich ${ }^{{ }^{*}}$ \\ 1- Departamento de Bioquímica, Instituto de Química, Universidade de São Paulo, 05508-000 São Paulo-SP, Brasil \\ 2- Laboratório de Genômica e Biologia Molecular do AC Camargo Câncer Center. \\ e-mail: henning@iq.usp.br; vankaren@gmail.com
}

\begin{abstract}
Resumo: O câncer de pulmão continua sendo uns dos tumores mais agressivos, com um prognóstico geralmente ruim, apesar dos avanços nas terapias personalizadas. A heterogeneidade dos tumores de pulmão sugere que estes podem ser originados a partir de células multipotentes. Diversos estudos já demonstraram que as células-tronco cancerosas estão envolvidas na iniciação e metástases do tumor. A falta de marcadores específicos para fenotipagem de células-tronco tumorais, dificultam a detecção destas células em amostras clínicas. A fim de obter-se uma ferramenta de diagnóstico mais acurado, estamos trabalhando no desenvolvimento de aptâmeros de DNA com ligação específica a células tumorais de pulmão.
\end{abstract}

Palavras-chaves: Câncer de pulmão, células-tronco cancerosas, aptâmeros.

\section{Development of aptamers as a diagnostic instrument for lung cancer}

\begin{abstract}
Lung cancer is one of the most aggressive tumors, with a generally poor prognosis. The cellular heterogeneity of tumor, resilience of cancer stem cells, and the lack of specific markers to detect and differentiate between various tumoral cell phenotypes in clinical materials hinders timely diagnosis. Novel diagnostic tools need to be developed that will specifically detect tumor cells and accelerate clinical characterization of the tumor. DNA aptamers have been developed and are being characterized for the selective interaction with lung cancer cells and detection of tumor cells in patients' samples.
\end{abstract}

Keywords: Aptamers, cytometry, lung cancer cells, cancer diagnostics.

\section{Introdução:}

O câncer de pulmão $(\mathrm{CP})$ é a causa mais comum de morte por câncer no mundo, uma vez que a detecção da doença ocorre principalmente em estágios avançados e está comumente associado ao tabagismo. Considerada uma patologia genética, o CP encontra-se fortemente relacionado a alterações moleculares que influem em sua patogênese, como as mutações de genes responsáveis pelo crescimento, pela proliferação e pela sobrevivência celular ${ }^{4,2}$. A heterogeneidade dos tumores de pulmão sugere que estes podem ser originados a partir de células multipotentes. Diversos estudos sugerem que as células-tronco cancerosas (CSC, do inglês cancer stem cells) podem ser a causa do crescimento de tumores e da resistência às terapias convencionais ${ }^{1}$. A falta de marcadores específicos para CSC dificulta a utilização da detecção destas células na determinação do prognóstico da doença na prática clínica. O grande desafio no campo da biologia do câncer é a descoberta de biomarcadores para tipos específicos de câncer e o desenvolvimento de sondas capazes de identificar estes alvos. Desta forma, o objetivo deste projeto foi o desenvolvimento de aptâmeros de DNA capazes de identificar a assinatura molecular de células tumorais de pulmão.

Aptâmeros são oligonucleotídeos selecionados capazes de reconhecer com grande especificidade epítopos proteicos, de maneira semelhante aos já conhecidos anticorpos monoclonais. Os aptâmeros possuem um potencial promissor em aplicações diagnósticas e terapêuticas, devido ao seu caráter não proteico, como resistência à degradação por ação enzimática, alta flexibilidade e especificidade, 
baixo peso molecular, baixa imunogenicidade e facilidade de produção/manipulação, competindo com anticorpos monoclonais ${ }^{3,5}$. O método de seleção de aptâmeros, SELEX (Systematic Evolution of Ligands by EXponential enrichment), utiliza-se de bibliotecas combinatórias de sequencias aleatórias de oligonucleotídeos (RNA ou DNA) capazes de enriquecer, por ciclos reiterativos de SELEX, ligantes com alta afinidade e especificidade para inúmeros alvos de seleção in vitro, incluindo antígenos expressos na superfície de células e membranas de células inteiras.

\section{Parte experimental:}

\section{Processo de seleção in vitro de Aptâmeros:}

Para a seleção dos aptâmeros e ensaios de seletividade de ligação, uma linhagem de câncer de pulmão de não pequenas células (NSCLC), histotipo adenocarcinoma (A549), foi utilizada. A seleção dos aptâmeros (SELEX) foi realizada em cinco ciclos. Observou-se um aumento de taxas de ligação no primeiro ciclo, quando $10 \mu \mathrm{M}$ de aptâmeros de fita simples foram incubados com $10^{6}$ células. Nos ciclos subsequentes, foram utilizados $1 \mu \mathrm{M}$ de aptâmeros, os quais foram incubados em tampão de seleção com as células por 10 minutos. Em cada ciclo, foram utilizadas concentrações menores de células $\left(10^{5}, 10^{4}, 10^{3}, 10^{2}\right)$. Após o período de incubação realizou-se as lavagens com tampão de seleção. Para aumentar a seletividade dos aptâmeros, foi adicionado t-RNA de levedura para o bloqueio de sítios de ligação não específica. Após 5 ciclos de $S E L E X$, a biblioteca de aptâmeros foi sequenciada por sequenciamento de nova geração (NGS-Illumina). As sequencias obtidas foram submetidas à análise de bioinformática. Com base de conservação de sequencias na região anteriormente aleatória e de predição de estruturas, foram selecionados 8 aptâmeros.

\section{Análise da taxa de ligação dos aptâmeros às células tumorais de linhagem de carcinoma pulmonar}

A avaliação por citometria de fluxo foi realizada em células tumorais de câncer de pulmão de não pequenas células (NSCLC), dos histotipos adenocarcinoma: A549 (CCL185) e carcinoma de células escamosas: H1299 (CRL5803), para determinar as ligações dos aptâmeros selecionados. A concentração utilizada de cada aptâmero foi de $25 \mathrm{nM}$ diluídos em $400 \mu \mathrm{l}$ tampão de ligação (pH $7,4)$. As células nativas $\left(2 \times 10^{5}\right.$ células) foram incubadas por 45 minutos com os aptâmeros selecionados à temperatura ambiente. Após incubação, as células foram centrifugadas a $200 \mathrm{X} \mathrm{g}$ por 5 minutos e lavadas 2 vezes em tampão de ligação. As células incubadas sem aptâmeros foram utilizadas como controle negativo $(\mathrm{CN})$. A leitura foi realizada a $517 \mathrm{~nm}$ (pico de emissão de fluorescência de carboxi-fluoresceína [FAM] com o citometro de fluxo Attune (Applied Biosystems). As análises foram realizadas em triplicatas para cada linhagem celular e os resultados foram relatados como \% de células marcadas.

\section{Ensaios de imunofluorescência para avaliação de ligação dos aptâmeros selecionados}

Os ensaios de imunofluorescência com marcação por aptâmeros, foram realizados com a linhagem H1299 (CRL5803). As células em suspensão, foram aplicadas (esfregaço) em uma lâmina de vidro até a secagem completa, em temperatura ambiente. Em seguida, os aptâmeros previamente ligados com FAM (517 nm), foram diluídos em tampão de ligação $(0,1 \mathrm{mM} / 100 u l, p H ~ 7,4)$, aplicados diretamente nas lâminas e incubados por 40 minutos. Para o controle negativo $(\mathrm{CN})$, as células foram incubadas com o tampão de ligação, sem os aptâmeros. Após o período de incubação, as amostram foram lavadas com PBS e permeabilizadas por 5 minutos na presença de PBS contendo 
0,1\% Triton-X100. Posteriormente, DAPI (4',6'-diamino-2-fenil-indol) foi aplicado por 10 minutos para a coloração de núcleo celular. Em seguida, as amostras foram lavadas com PBS. As lâminas foram montadas com meio de montagem (Fluoromount), e, posteriormente, observadas no microscópio confocal invertido TissueFAXS (TissueGnostics).

\section{Resultados e Discussões:}

A Figura 1 demonstram estruturas típicas dos aptâmeros selcionados. Estas estruturas 2D dos aptâmeros foram modeladas usando uma ferramenta online UNA Fold do Integrated DNA Technologies. Confirmamos a ligação destes aptâmeros para as células tumorais. Nestes ensaios, os aptameros foram submetidos a análise por citometria de fluxo para validação da capacidade de ligação às células tumorais in vitro.
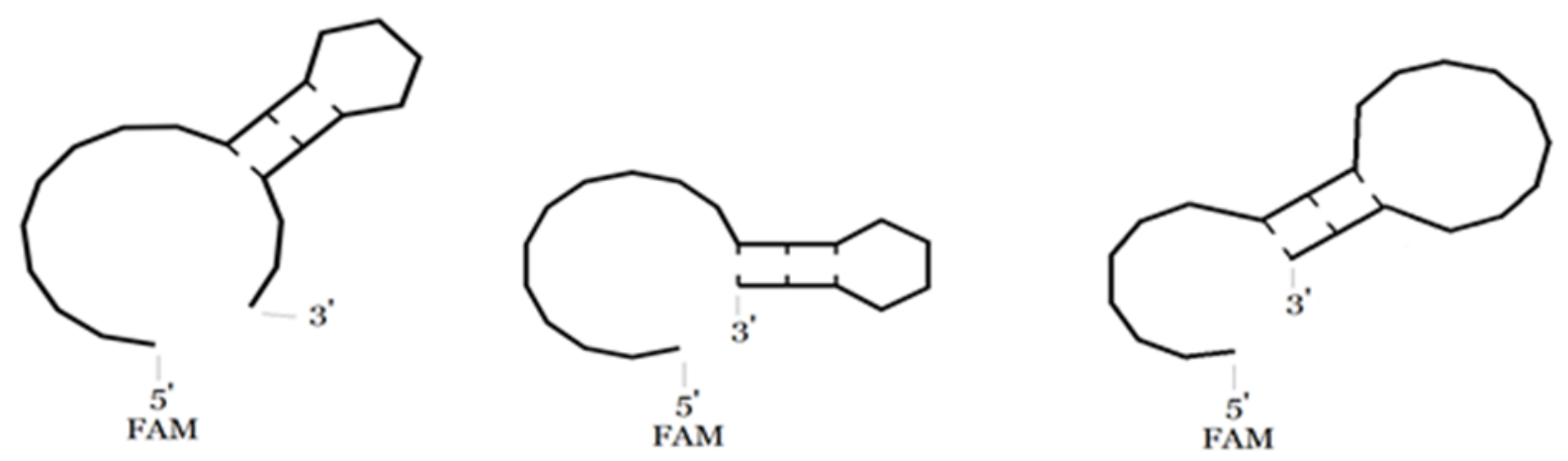

Figura 1: Ilustração de estruturas secundarias dos aptâmeros selecionados. As seguintes condições foram estabelecidas para modelagens das estruturas: $25{ }^{\circ} \mathrm{C} ; 143 \mathrm{nM} \mathrm{Na} 2+; 1,26 \mathrm{mM} \mathrm{Mg} 2+$. As estruturas 2D dos aptâmeros foram modeladas usando uma ferramenta online UNA Fold do Integrated DNA Technologies (https://www.idtdna.com/UNAFold).

Na Figura 2 mostram os resultados por citometria de fluxo, onde a células da linhagem A549 marcadas com o denominado aptâmeros 3, mostram a capacidade deste aptâmero em reconhecer uma sub-população de células tronco na linhagem A549 em torno de 5\% do total das células. E célula da linhagen H1299 marcada com o denominado aptâmero 7, mostram a capacidade deste aptâmero em reconhecer uma sub-população de células tronco na linhagem H1299 em torno de 8\% do total das células. 
A

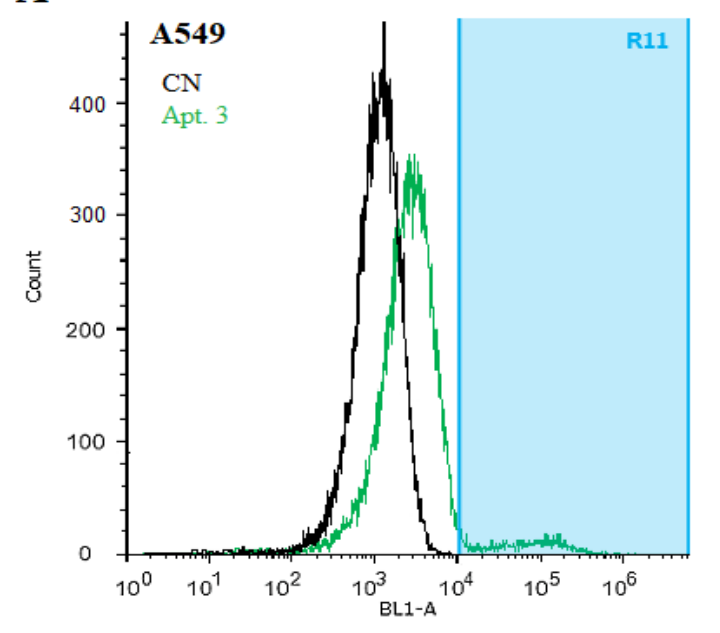

$\mathbf{C}$

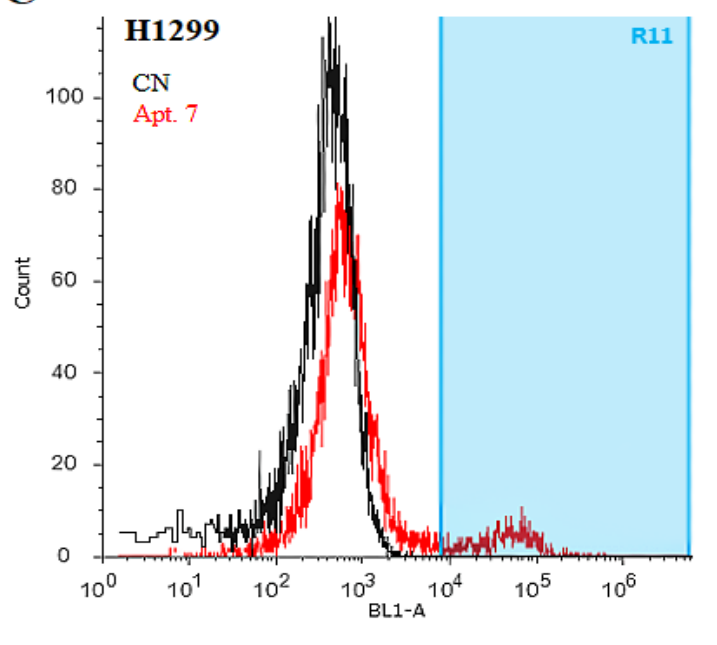

D

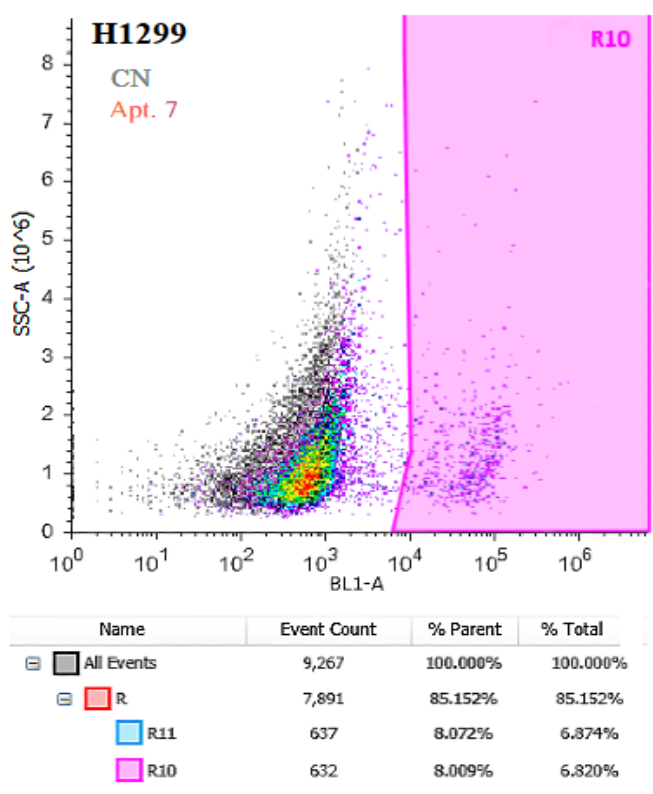

Figura 2: Avaliação por citometria de fluxo das linhagens A549 e H1299 marcadas com aptâmeros. Na figura $\mathrm{A}$ e $\mathrm{B}$, os density plots mostram a presença de uma população secundária, bem definida, que é marcada com o denominado aptâmero 3, sugerindo uma capacidade deste aptâmero em reconhecer uma subpopulação de células tronco na linhagem A549 em torno de 5\% do total das células. Na figura C e D, os density plots mostram a presença de uma população secundária que é marcada por o denominado aptâmero 7, demonstrado a capacidade deste aptâmero em reconhecer uma subpopulação de células tronco na linhagem H1299, com marcação em torno de $8 \%$ do total da população.

Os ensaios de imunofluorescência foram realizados com a linhagem H1299, marcadas com o denominado aptâmero 7. Na Figura 3 mostram a imunomarcação do citoplasma das células H1299 com o aptâmero selecionado. Os resultados demostram a capacidade do aptâmero em reconhecer as células da linhagem H1299. 


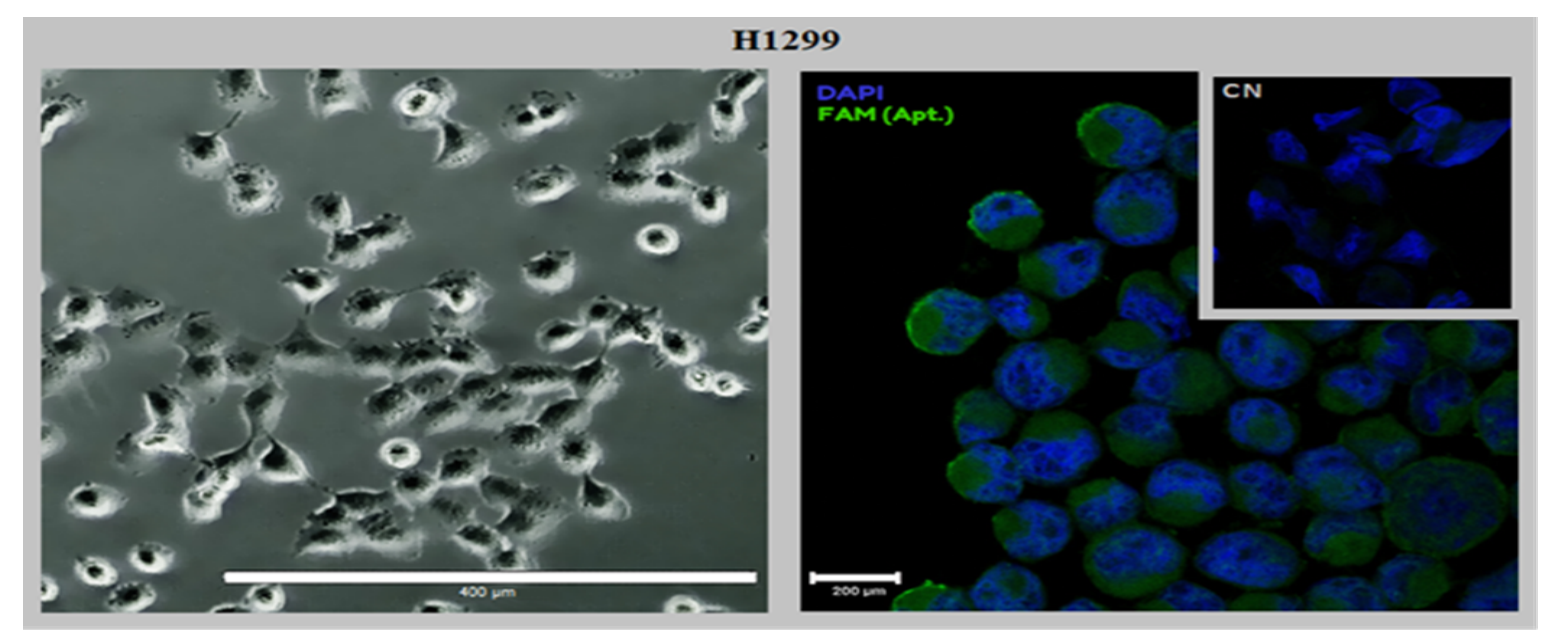

Figura 3. Marcação de células H1299 pelo aptâmero 7 em ensaios de imunofluorescência. A figura A, mostra a morfologia do carcinoma de células escamosas da linhagem H1299, por microscopia de campo claro. A figura B, mostra a imunomarcação citoplasmática do aptâmero 7 (verde). Figura C: controle negativo, sem marcação para aptâmero e positivo para DAPI (núcleo).

\section{Conclusão:}

Durante a etapa do SELEX, foram selecionados 8 aptâmeros com estrutura mais estável e maior a força de especificidade de ligação nas células tumorais de pulmão. Desta maneira, os aptâmeros selecionados foram avaliados por ensaios de citometria de fluxo e imunofluorescência, onde dois tipos histotipos de NSCLC (adenocarcinoma e carcinoma de células escamosas, A549 e H1299, respetivamente) foram utilizados com a finalidade de validar a capacidade de ligação de cada aptâmero.

Nos ensaios de citometria de fluxo, a porcentagem de células positivas para cada um dos aptâmeros apresentaram uma capacidade de ligação delimitada. Os resultados de imunofluorescência reforçam os resultados da citometria de fluxo, evidenciando a ligação dos aptâmeros nas células tumorais. Estamos trabalhando com outros fenótipos de NSCLC e melhorando o método experimental, com a finalidade de aumentar a eficiência de detecção das células tumorais, através dos aptâmeros, bem como validá-los em amostras clinicas de pacientes com câncer de pulmão.

\section{Agradecimentos:}

Agradecemos ao apoio financeiro do CNPq (306392/2017-8), FAPESP (2018/07366-4) e CAPES (Código 001).

\section{Bibliografias:}

1- Ayob AZ, Ramasamy TS. J Biomed Sci. 2018, 25: 20.

2- Christiansen JJ, Rajasekaran AK. Cancer Research. 2006, 66 (17): 8319-8326.

3- Nery AA, Wrenger C. \& Ulrich H. Journal of Separation Science. 2009, 32:1523-1530.

4- Sá VK, et al. Human Pathology. 2012, 43 (5): 675-683.

5- Šmuc T, et al. Journal of Pharmaceutical and Biomedical Analysis. 2013, 81-82:210-217. 